\title{
Effective Chloride Removal in Reinforced Concrete Using Electrochemical Method in the Presence of Calcium Nitrite
}

\author{
Jiajun Huang ${ }^{1, *}$ and Ang Wang ${ }^{2}$ \\ ${ }^{1}$ School of Civil Engineering and Architecture, Xinxiang University, Xinxiang, 453000, P.R. China \\ ${ }^{2}$ Huanghe Science and Technology College, Kaituo Rd, Erqi, Zhengzhou 450006, P.R. China \\ *E-mail: jiajunhuangxx@126.com
}

doi: $10.20964 / 2016.06 .53$

Received: 8 March 2016 / Accepted: 6 April 2016 / Published: 4 May 2016

\begin{abstract}
Repairing reinforced concrete is an important issue in the construction industry. Electrochemical chloride extraction is an effective method for repairing reinforced structures. On the other hand, the widely use of corrosion inhibitors becomes another approach, which as a protective strategy for reinforcement against corrosion. The corrosion inhibitor can penetrate and migrate in an electric field, which could potentially enhance the inhibition performance. In this work, we proposed a simple electrochemical chloride extraction method that simultaneously can enhance the corrosion inhibitor molecule penetration. Several electrochemical methods were used for analyzing the performance of the proposed method, including corrosion potential measurement and polarization resistance measurement. Moreover, visual inspection was also used for confirming the effectiveness of the proposed method.
\end{abstract}

Keywords: Electrochemical chloride extraction; Corrosion; Concrete; Polarization resistance; Corrosion potential

\section{FULL TEXT}

(C) 2016 The Authors. Published by ESG (www.electrochemsci.org). This article is an open access article distributed under the terms and conditions of the Creative Commons Attribution license (http://creativecommons.org/licenses/by/4.0/). 